LETTER TO JMG

\title{
Novel association of hypertrophic cardiomyopathy, sensorineural deafness, and a mutation in unconventional myosin $\mathrm{VI}$ (MYO6)
}

\author{
S A Mohiddin, Z M Ahmed, A J Griffith, D Tripodi, T B Friedman, L Fananapazir, R J Morell
}

J Med Genet 2004;41:309-314. doi: 10.1136/jmg.2003.011973

F amilial hypertrophic cardiomyopathy (FHC) is typically characterised by left ventricular hypertrophy, diastolic dysfunction, and hypercontractility, and is often associated with disabling symptoms, arrhythmias, and sudden death. ${ }^{1}$ FHC shows both non-allelic and allelic genetic heterogeneity, and results from any one of more than 100 mutations in genes encoding sarcomeric proteins. ${ }^{2}$ Identified genes include those encoding $\beta$ myosin heavy chain, the myosin regulatory and essential light chains, myosin binding protein $\mathrm{C}$, troponin $\mathrm{I}$, troponin $\mathrm{C}, \alpha$ cardiac actin, and titin. ${ }^{2}{ }^{3}$ The FHC phenotype is characterised by hypertrophy, myocyte disarray and fibrosis, and results from the dominant negative expression of one of these (mainly missense) mutations. The resulting sarcomeric dysfunction leads ultimately, through mechanisms that remain obscure, to pathological left ventricular remodelling. However, as molecular defects are identified in only half the cases, it is likely that non-sarcomeric genes may also be responsible. Non-sarcomeric causes of FHC are largely uncharacterised, and may be associated with distinct or compound phenotypes.

Similarly, hereditary sensorineural hearing loss shows a great degree of non-allelic and allelic genetic heterogeneity, and can be dominant, recessive, $\mathrm{X}$ linked, or mitochondrial. ${ }^{4-6}$ Hereditary sensorineural hearing loss is classified according to mode of inheritance and the presence of clinically detectable extra-auditory manifestations (syndromic deafness) or their absence (non-syndromic). ${ }^{67}$ The distributions of mutant gene expression are not necessarily restricted to clinically affected organ systems, and mutant genes associated with "non-syndromic" deafness may therefore have subtle extra-auditory manifestations.

Genetic syndromes restricted to a cardio-auditory phenotype include the long QT syndrome (LQTS) caused by mutations in KvLQT1 (KCNQ1) or in KCNE1, where QT prolongation has autosomal dominant expression (Romano Ward syndrome), but congenital sensorineural hearing loss with LQTS is autosomal recessive (Jervell and Lange-Nielsen syndrome) ${ }^{8}$ In the LQTS, cardiac structure is normal. Recently, Schonberger et al described a syndrome of dilated cardiomyopathy and sensorineural hearing loss which was linked to 6q23-24 in two families. ${ }^{9}$ dilated cardiomyopathy and sensorineural hearing loss penetrance were both age related, although sensorineural hearing loss onset was at a much younger age and appears to have been more penetrant.

Here we describe a pedigree co-segregating progressive, late onset, autosomal dominant sensorineural hearing loss, QT interval prolongation, and cardiac hypertrophy. Linkage analysis indicates that the causative gene is located on chromosome 6q12. We have identified a mutation in MYO6, a gene encoding a non-muscle or unconventional myosin, in all affected members of the pedigree.

\section{Key points}

- Familial hypertrophic cardiomyopathy (FHC) is typically confined to a cardiac phenotype and is caused by mutations in genes encoding sarcomeric proteins. Occasionally FHC may be one component of a hereditary multisystem disorder.

- Sensorineural hearing loss is genetically heterogeneous. Mutations in the MYO6 gene, encoding unconventional myosin $\mathrm{VI}$, have been found to cause non-syndromic sensorineural hearing loss-that is, sensorineural hearing loss in the absence of any other related clinical features.

- 36 members of a kindred in which autosomal dominant sensorineural hearing loss co-segregates with $\mathrm{FHC}$ were evaluated by history, physical examination, ECG, echocardiography, and audiometry. Ten had sensorineural hearing loss, and four also had FHC. Six had sensorineural hearing loss without echocardiographic evidence of left ventricular hypertrophy. Four of these six patients had abnormalities on 12 lead ECG, and three of the six had prolongation of the QT interval. Cardiac symptoms were mild or absent in most affected family members. Genetic analyses suggested linkage of a cardio-auditory phenotype to a region at $6 q 13$ encompassing the MYO6 locus. A novel missense mutation (H246R) of MYO6 affecting the highly conserved motor domain was detected in all affected members.

- A cardio-auditory syndrome may be associated with a dominant missense mutation in a gene encoding an unconventional myosin. The cardiac manifestations can escape detection in pedigrees with MYO6 associated sensorineural hearing loss. Careful cardiological characterisation of these families may clarify the aetiological relations among $\mathrm{FHC}$, sensorineural hearing loss, and myosin VI.

\section{METHODS}

\section{Subjects}

Subjects were studied according to NHLBI (98-H-0100 and 99-H-0065) and NIDCD (97-DC-0180) protocols approved by the respective institutional review boards. Written consent

Abbreviations: FHC, familial hypertrophic cardiomyopathy; LOD, logarithm of odds; LQTS, long QT syndrome; PTA, pure tone averages; STR, short tandem repeat 
was obtained from all family members who participated in the study. Family members were evaluated by interview, clinical examination, 12 lead ECG, transthoracic echocardiography, pure tone and speech audiometry, tympanometry, and acoustic reflex testing.

\section{Clinical evaluation}

FHC was diagnosed when echocardiographic measurements of left ventricular wall dimensions were greater than $13 \mathrm{~mm}$ in the absence of other causes of left ventricular hypertrophy. The QT interval was determined manually from the 12 lead ECG by an experienced electrophysiologist blinded to patient identity and the results of audiological evaluations, and the corrected QT (QTc) was calculated using the Bazett formula. The QTc was considered prolonged if it was $\geqslant 470 \mathrm{~ms}$ in male subjects and $\geqslant 480 \mathrm{~ms}$ in female subjects. ${ }^{10}$ Pure tone audiometry was done at $0.25,0.5,1,2,4,6$, and $8 \mathrm{kHz}$ for air conduction and at $0.5,1,2$, and $4 \mathrm{kHz}$ for bone conduction. Pure tone averages (PTA) were calculated for air conduction thresholds at 0.5, 1, 2 and $4 \mathrm{kHz}$. Individuals were considered affected if they showed bilateral PTA greater than the 95th centile when compared with age and sex adjusted normative data. ${ }^{11}$

\section{Genetic analysis}

Genomic DNA was obtained from peripheral blood using standard protocols (Puregene, Gentra). Polymerase chain reaction (PCR) of polymorphic short tandem repeat (STR) markers was undertaken with fluorescent dye labelled primers, and STR amplicons were analysed on an ABI 377 DNA sequencer using Genescan and Genotyper software (Applied Biosystems). After excluding linkage to several known loci for sensorineural hearing loss and LQTS, a genome-wide scan was carried out using the Weber v.9a marker set ( $10 \mathrm{cM}$ resolution) (Marshfield Medical Research Foundation). Two point logarithm of odds (LOD) scores were calculated using the FASTLINK version of the LINKAGE software package. ${ }^{12}{ }^{13}$ Individuals were assigned to one of three liability classes based on the sensorineural hearing loss phenotype: class 1 (age $>50), 95 \%$ penetrance and 1/100 phenocopy rate; class 2 (age 25 to 50 ), 90\% penetrance and 1/1000 phenocopy rate; and class 3 (age $<25)$, 30\% penetrance and 1/10 000 phenocopy rate. Simulated LOD scores were generated using SLINK ${ }^{13} 14$ and calculated under the assumptions described above. Additional simulations were based on the cardiac phenotype alone and a single, highly penetrant, syndromic trait. MYO6 was evaluated for mutations using previously described primer pairs and direct sequencing using Big-Dye Terminators v.3 (Applied Biosystems). ${ }^{15}$

\section{RESULTS \\ Clinical findings}

The proband (III-3) was diagnosed with hypertrophic cardiomyopathy at the age of 35 years following evaluation for exertional dyspnoea and chest pain (fig 1). Several episodes of presyncope and syncope had occurred since age 20. One episode of self limiting atrial fibrillation was associated with severe presyncope. A 12 lead ECG showed sinus rhythm, left atrial hypertrophy, left axis deviation, a q wave in lead AVL, biphasic septal T waves, and a corrected QT interval $\left(\mathrm{QT}_{\mathrm{c}}\right)$ of $584 \mathrm{~ms}$ (fig 2). Transthoracic echocardiography showed a non-dilated and hyperdynamic left ventricle, systolic anterior motion of the mitral valve, and normal left ventricular outflow velocities. Magnetic resonance imaging of the heart measured the anterior septum to be $21 \mathrm{~mm}$, posterior wall $12 \mathrm{~mm}$ (normal septum and posterior wall dimensions 6-11 mm), ejection fraction $65 \%$, and left ventricular mass $270 \mathrm{~g}$ (mean (SD) in normal adults, 87 (12) g) (fig 3). There was no family history of syncope or sudden death at a young age.

The proband had bilateral, symmetrical, mild to severe sensorineural hearing loss affecting high frequencies to the greatest degree, resulting in a downsloping audiometric configuration. The onset was in the early postlingual period of the first decade of life, followed by steady and gradual progression. Speech audiometry and acoustic reflex testing results were consistent with cochlear hearing loss. A history of progressive hearing loss affecting several generations within the family was evident, suggesting autosomal dominant inheritance. The onset and natural history of sensorineural hearing loss was similar in other affected family members (age range 5 to 54 years). The two youngest affected subjects had sensorineural hearing loss affecting only middle and low frequencies (at five and 10 years of age). In contrast, affected adults had hearing loss affecting all frequencies to varying degrees, with a variety of audiometric configurations. The highest observed pure tone average (0.5/ $1 / 2 / 4 \mathrm{kHz}$ ) in the better hearing ear was $55 \mathrm{~dB}-\mathrm{HL}$ in subject III-2, who was 43 years old (fig 4 ).

Clinical evaluation of family members subsequently determined that other family members who have sensorineural hearing loss also have ECG and echocardiographic abnormalities (table 1). The most typical phenotype includes bilateral low frequency sensorineural hearing loss, progressive in severity from the end of the first decade of life, apical left ventricular hypertrophy, and a prolonged QT interval. In the youngest family member (IV-6, aged five years) with early signs of sensorineural hearing loss, no ECG or echocardiographic abnormalities were detected, and in another with early sensorineural hearing loss (IV-3, aged 10 years), the ECG showed right axis deviation, left atrial hypertrophy, and increased voltages despite a normal echocardiogram. Family member II-3 was not evaluated in our audiological clinic (aged 74 years) and is reported to have a late onset hearing loss and several ECG abnormalities, and has inferior wall hypokinesia, mitral annular calcification, and mitral and aortic valve regurgitation on echocardiography. She has no descendants with sensorineural hearing loss or cardiomyopathy. It was thought that this individual was both a cardiac and auditory phenocopy. There were no instances of ECG abnormalities detected in individuals with normal hearing. We concluded that a possible cardioauditory syndrome was segregating in this family, with sensorineural hearing loss as the most penetrant feature.

\section{Genetic analysis}

The pedigree structure and size of family 641 (fig 1) allows a simulated maximum LOD score of 4.4, assuming a dominant, syndromic trait with greater than $90 \%$ penetrance in all generations. Consideration of the cardiac phenotype resulted in maximum simulated LOD scores of only 1.8 (assuming $50 \%$ penetrance for hypertrophic cardiomyopathy $\left.{ }^{16}\right)$. After excluding loci associated with familial sensorineural hearing loss (at that time), we did a $10 \mathrm{cM}$ resolution genome-wide scan. Affection status for the purposes of linkage analysis was determined by the presence of sensorineural hearing loss. Individuals were assigned to one of three liability classes, based on the hearing loss phenotype: class l (age > 50), 95\% penetrance and 1/100 phenocopy rate; class 2 (age 25 to 50), $90 \%$ penetrance and 1/1000 phenocopy rate; class 3 (age $<25)$, $30 \%$ penetrance and 1/10 000 phenocopy rate. No markers showed perfect co-segregation with the sensorineural hearing loss phenotype. The maximum LOD score obtained was 2.98 with marker D6S1681 at 6q13. Analyses with additional markers at $6 \mathrm{q} 13$ showed that all affected individuals had the same haplotype spanning $30 \mathrm{cM}$ (D6S1017 to D6S1031). Two individuals, IV-1 and IV-10, 


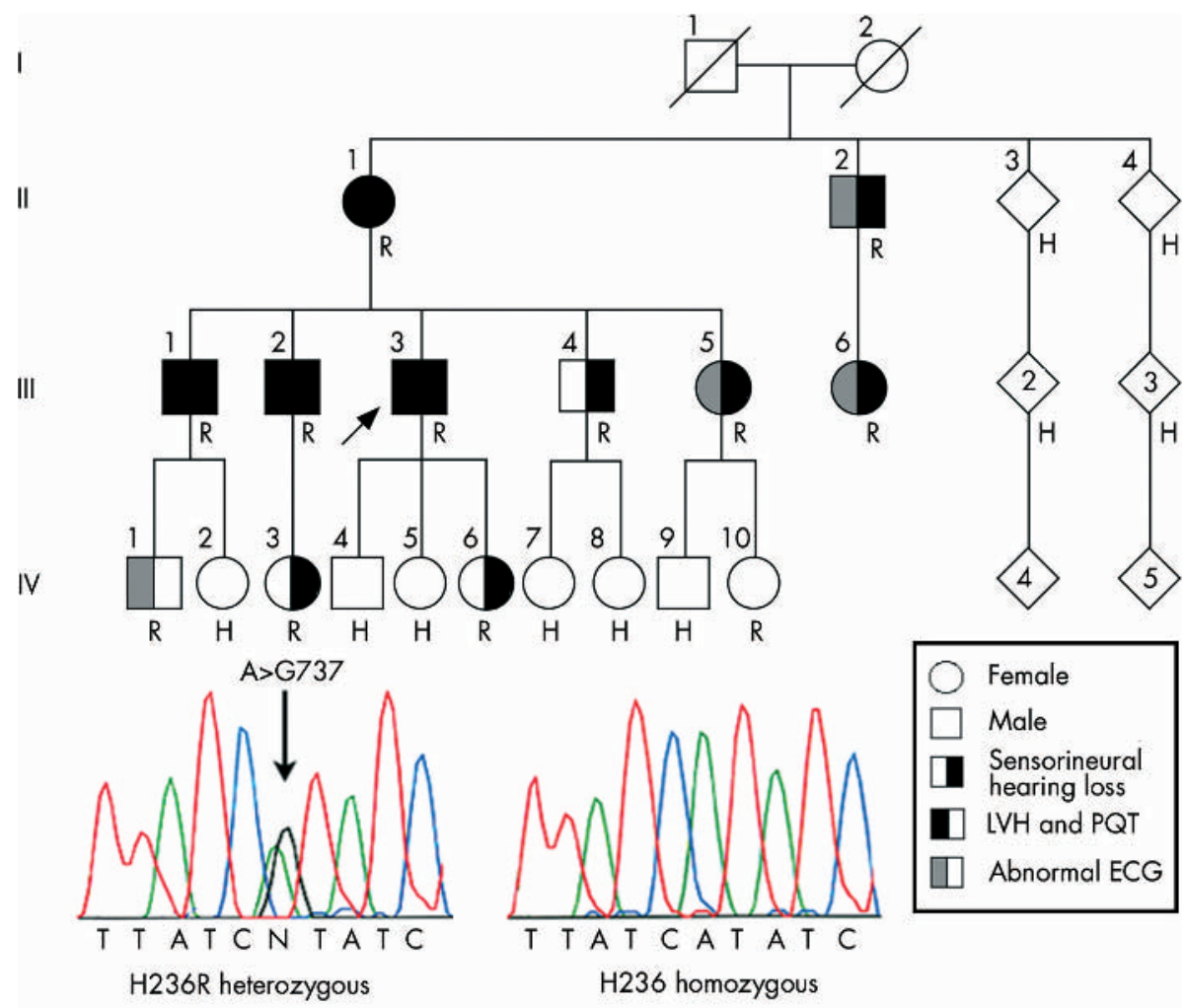

Figure 1 Pedigree: genotype and phenotype are summarised on the pedigree. Several descendants of II-3 and II-4 were studied; none had cardiomyopathy or sensorineural hearing loss and have been omitted from the pedigree to promote anonymity. Also shown are sequencing pherograms illustrating heterozygosity for histidine and arginine at position 246 of MYO6 (H246R) and homozygosity for the normal allele (His246).

$\|-1$

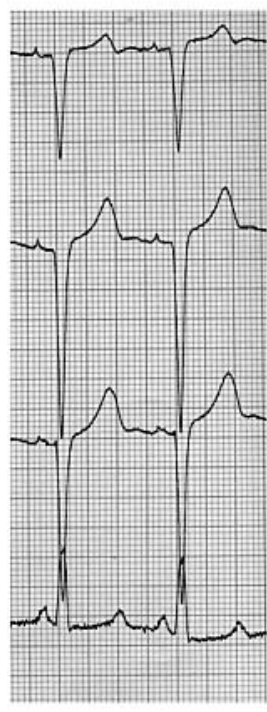

॥-2

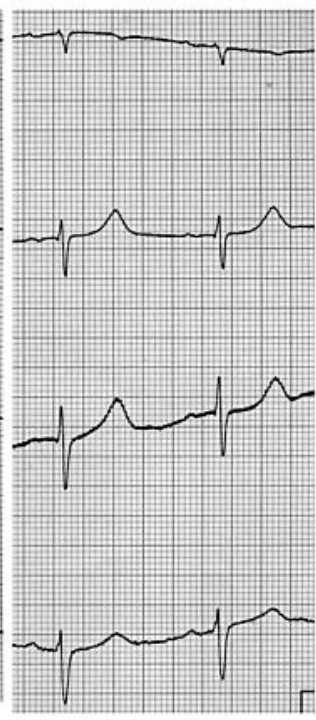

III-2

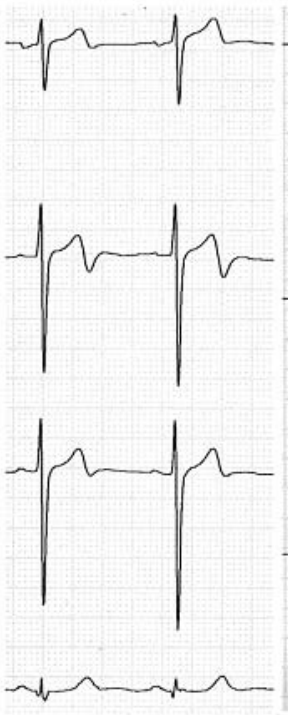

III-3
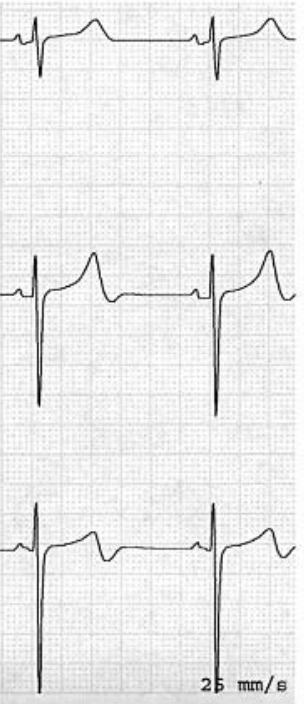

$111-5$

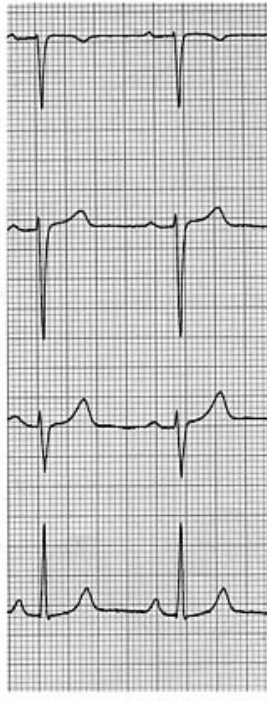

IV-6
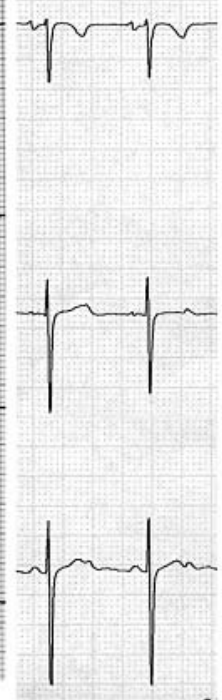

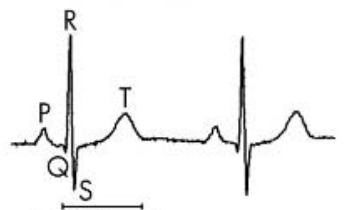

QT interval

Figure 2 ECGs from family members with the MYO6 mutation. Leads V1-V3 are shown for all; lead II is also shown for II-1, II-2, III-2 and III-5. All ECGs recorded at $10 \mathrm{~mm} / \mathrm{mV}$ at rate $25 \mathrm{~mm} / \mathrm{s}$. II- 1, III-2, and III-3 all have left ventricular hypertrophy on echocardiography. II-2, III-5, and IV-6 had normal echocardiograms. II-2 has a very prolonged QT interval and III-5 has borderline first degree heart block. The ECG in IV-6 was considered normal for age (five years). A stylised recording is shown at bottom to identify the component waves of the ECG (P, Q, R, S, and T) and the QT interval. 

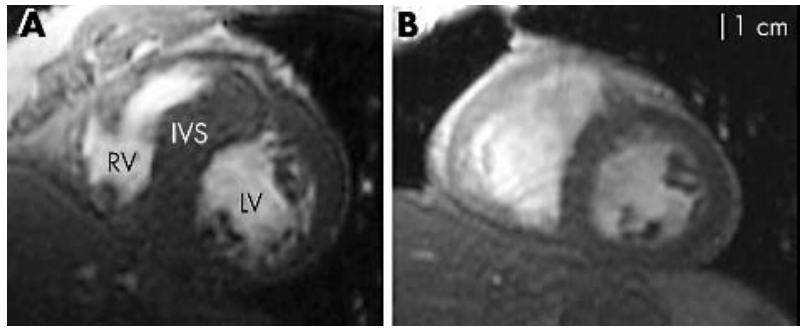

Figure 3 Magnetic resonance cardiac imaging in proband III-3. The panel on the left is a short axis view of the patient's mid left ventricle in cross section; a normal left ventricle is shown in the panel on the right for comparison. Both images are to the same scale. There is marked hypertrophy of the proband's left ventricular walls, particularly of the intraventricular septum. IVS, intraventricular septum; LV, left ventricle; $\mathrm{RV}$, right ventricle.

who were normal on audiological examination at ages 12 and 28 years, respectively, also inherited this haplotype, raising the possibility of incomplete penetrance.

Genes localised to chromosome 6q13 include KCNQ5 and MYO6 encoding non-muscle myosin VI; the latter was recently associated with dominant (DFNA22) and recessive (DFNB37) non-syndromic sensorineural deafness. ${ }^{15}{ }^{17}$ Given that mutations of KCNQ4 cause non-syndromic deafness (DFNA2) and mutations of KCNQI cause the cardio-auditory phenotype Jervell and Lange-Nielson syndrome, we first sequenced the coding exons of the paralogous gene, $K C N Q 5 .^{18} 19$ No mutations in KCNQ5 were found among affected members. Sequence analysis of the coding exons of MYO6 showed a novel transition mutation, 737A $>\mathrm{G}$, in all affected members of family 641 . This is predicted to lead to the replacement of a conserved histidine residue with arginine in the motor region of the myosin VI protein (H246R, fig 5). This mutation was not detected in the genomic DNA from 351 individuals of a wide variety of ethnic backgrounds (702 chromosomes). Phospholamban (PLN), a gene recently associated with dilated cardiomyopathy localised to 6q22.1, was also sequenced to test the hypothesis that the sensorineural hearing loss and FHC phenotypes were aetiologically independent but associated, owing to the physical linkage of the causative genes on chromosome $6{ }^{20}$ No mutations in PLN were identified following sequencing of several affected individuals.

\section{DISCUSSION}

We describe the novel association of progressive, postlingual autosomal dominant sensorineural hearing loss and hypertrophic cardiomyopathy. There is a previous report of profound prelingual autosomal dominant hearing loss associated with FHC. ${ }^{21}$ In our pedigree, linkage and mutation analyses implicate a missense allele (H246R) of the myosin VI gene (MYO6). Another missense allele of MYO6 (C442Y) was recently identified as the cause of dominantly inherited and progressive sensorineural hearing loss (DFNA22); no other clinical features were reported in the affected individuals. ${ }^{17}$ No cardiac abnormalities were detected in affected individuals with recessive missense mutations in MYO6 (DFNB37). ${ }^{15}$ In the mouse, mutations of Myo6 cause hearing loss and vestibular dysfunction, with no other phenotype reported $^{22-24}$; however, MYO6 expression in the human heart was demonstrated by northern blot. ${ }^{25}$ The cardiological phenotype reported here may suggest that only certain MYO6 mutations are associated with cardiomyopathy. In our study, the cardiac findings are relatively benign and mild in all except the proband. Unless echocardiograms and ECGs are part of the clinical evaluation, a mild or incompletely penetrant cardiac phenotype may be overlooked. Lastly, we cannot exclude the possibility that the cardiac and sensorineural hearing loss phenotypes in family 641 are unrelated.

The histidine to arginine mutation affects the highly conserved motor region of myosin VI. Myosin VI is a nonmuscle (unconventional) myosin with a property distinct from most other myosins-most myosins have motor activity towards the "plus end" of actin filaments; dimers of myosin VI are directed towards minus end. ${ }^{26-28}$ Several non-muscle myosins have been associated with human hearing. ${ }^{27-31}$

FHC typically results from mutations affecting sarcomeric genes that encode components of the myocyte contractile

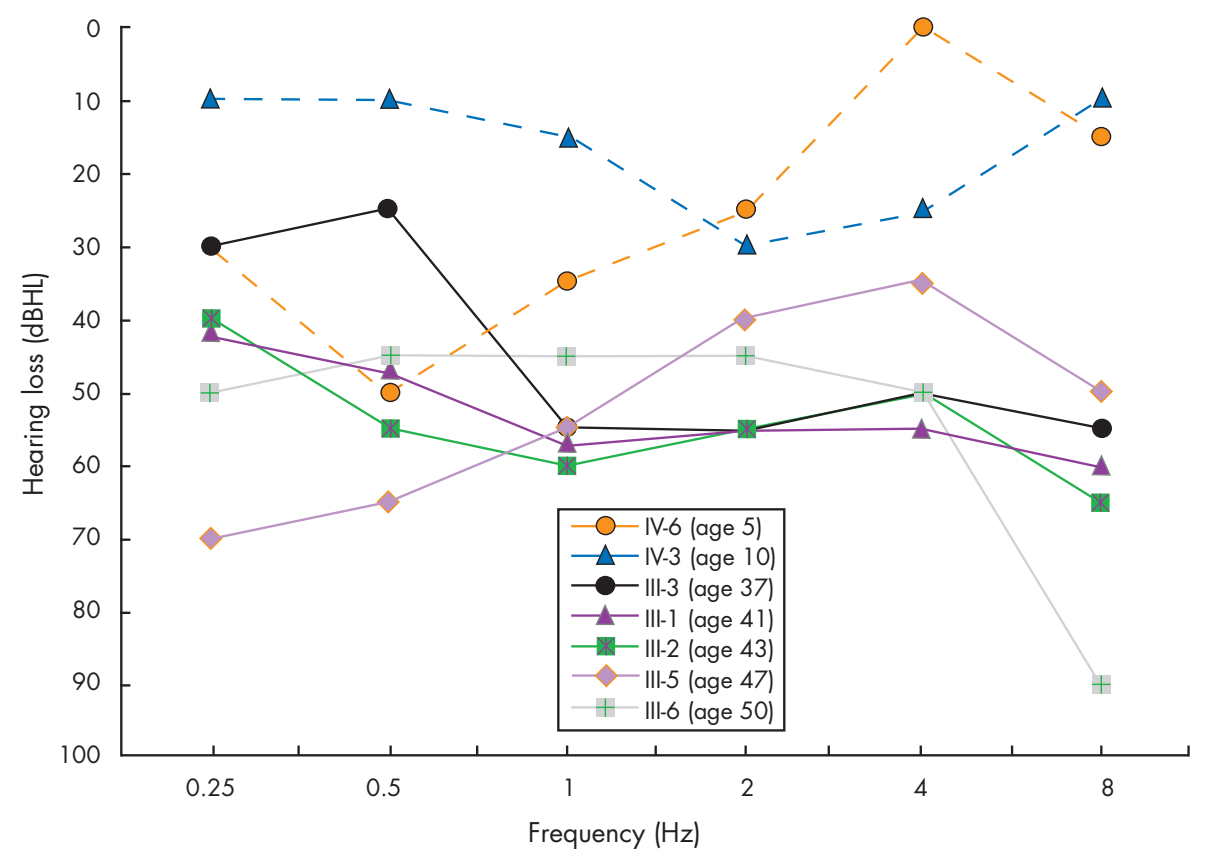

Figure 4 Composite pure tone audiograms from the better ears of affected individuals of family 641. The rates of progression and audiogram configurations are highly variable, although all affected subjects were consistent in that the hearing loss was bilateral and sensorineural. 
Table 1 Clinical details on selected members of the pedigree; individuals can be identified from fig 1

\begin{tabular}{|c|c|c|c|c|c|c|}
\hline \multirow[b]{2}{*}{ Individual } & \multirow{2}{*}{$\begin{array}{l}\text { Age } \\
\text { (years) }\end{array}$} & \multirow[b]{2}{*}{ MYO6 } & \multirow{2}{*}{$\begin{array}{l}\text { Sensorineural } \\
\text { hearing loss }\end{array}$} & \multicolumn{2}{|l|}{ ECG } & \multirow[b]{2}{*}{ ECHO } \\
\hline & & & & QTc (ms) & Other ECG abnormalities & \\
\hline$\|-1$ & 75 & Mutant & Yes & 581 & q wave in lead $A V L ; L V H ; L A H ; L B B B$ & $\begin{array}{l}\text { Apical LVH, SAM, hyperdynamic non- } \\
\text { dilated }\end{array}$ \\
\hline$\|-2$ & 89 & Mutant & Yes & 529 & Borderline $1^{\circ} \mathrm{HB}$ & Normal for age \\
\hline $11-3^{*}$ & 74 & wild-type & No & 572 & 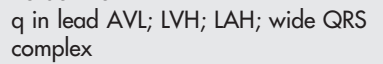 & Mild Al, $\bmod \mathrm{MR}$, inferior hypokinesia \\
\hline III-1 & 39 & Mutant & Yes & 468 & $\mathrm{q}$ in leads III, AVF & Apical LVH \\
\hline III-2 & 43 & Mutant & Yes & 505 & $\begin{array}{l}\text { q in leads II, III, AVR; post hemi } \\
\text { block; biphasic + waves }\end{array}$ & Apical LVH, trivial SAM \\
\hline III-3 & 36 & Mutant & Yes & 584 & $\begin{array}{l}q \text { in lead AVL; LAD; LAH; biphasic } \\
\text { t waves }\end{array}$ & Septal LVH \\
\hline III-4 & 50 & Mutant & Yes & 435 & Normal & Normal \\
\hline III-5 & 47 & Mutant & Yes & 459 & Borderline $1^{\circ} \mathrm{HB}$; $\mathrm{LAH}$ & Normal \\
\hline III-6 & 50 & Mutant & Yes & 510 & None & Not available \\
\hline IV-1 & 12 & Mutant & No & 509 & Borderline QT elevation & Normal \\
\hline IV-3 & 10 & Mutant & Yes & 447 & LAH; RAD possibly normal for age & Normal \\
\hline IV-6 & 5 & Mutant & Yes & 424 & None & Normal \\
\hline IV-10 & 28 & Mutant & No & 425 & None & Normal \\
\hline
\end{tabular}

*II-3 was considered a double phenocopy with presbycusis and cardiac abnormalities consistent with valvar and ischaemic disease. Prolonged QTc durations are in bold type.

$\mathrm{Al}$, aortic valve incompetence; ECHO, echocardiographic findings; LAH, left atrial hypertrophy; LBBB, left bundle branch block; LVH, left ventricular hypertrophy; $M R$, mitral valve regurgitation; RAD, right axis deviation; $S A M$, systolic anterior motion of the mitral valve; $1^{\circ} \mathrm{HB}$, first degree atrioventricular block.

MYO6 mutant $\mathrm{H} 246 \mathrm{R}$

\begin{tabular}{|c|c|c|c|c|c|c|c|c|c|c|c|c|c|c|c|c|c|c|c|}
\hline & & & 240 & & & & & & 246 & & & & 250 & & & & & & \\
\hline $\mathrm{H} 246 \mathrm{R}$ & $Q$ & $G$ & $\mathrm{~K}$ & $E$ & $E$ & $R$ & $N$ & Y & $R$ & I & $F$ & $Y$ & $R$ & L & C & A & $G$ & A & $S$ \\
\hline Human & $Q$ & G & K & $E$ & $E$ & $R$ & $N$ & Y & $\mathrm{H}$ & I & $F$ & $Y$ & $R$ & L & C & A & G & A & $S$ \\
\hline Pig & $Q$ & G & K & $E$ & $E$ & $R$ & $\mathrm{~N}$ & Y & $\mathrm{H}$ & I & $F$ & $Y$ & $R$ & L & C & A & G & A & $S$ \\
\hline Mouse & $Q$ & G & K & $E$ & $E$ & $R$ & $N$ & $\mathrm{H}$ & $\mathrm{H}$ & I & $F$ & $Y$ & $R$ & L & C & A & G & A & $S$ \\
\hline Chicken & $Q$ & $G$ & K & $E$ & $E$ & $R$ & $N$ & Y & $\mathrm{H}$ & I & $F$ & $Y$ & $R$ & L & C & A & G & A & $P$ \\
\hline Sea urchin & $Q$ & $N$ & G & $E$ & $E$ & $\mathrm{R}$ & $N$ & Y & $\mathrm{H}$ & V & $F$ & Y & Y & L & C & A & G & A & $P$ \\
\hline Sea bass & $Q$ & $S$ & $N$ & $D$ & $E$ & $R$ & $\mathrm{~N}$ & $Y$ & $\mathrm{H}$ & I & $F$ & $Y$ & $R$ & L & C & A & $G$ & A & $S$ \\
\hline Drosophila & $Q$ & $S$ & A & $E$ & $\mathrm{E}$ & $R$ & $\mathrm{~N}$ & Y & $\mathrm{H}$ & V & $F$ & $Y$ & $M$ & L & L & A & $G$ & A & $P$ \\
\hline
\end{tabular}

Figure 5 MYO6 residue $\mathrm{H} 246$ is conserved across species.

apparatus. $^{2}$ More recently, non-sarcomeric causes of FHC have been identified, but none of these genes encodes a non-muscle myosin. Transgenic knockouts of non-muscle myosin II-B develop severe structural cardiac defects similar to human congenital heart disease, suggesting that at least some unconventional myosins are required for normal cardiac development. ${ }^{32}$ There is no evidence for congenital cardiac abnormalities in the family we report here. Rather, like the hearing abnormality, penetrance of the cardiomyopathy is age related, suggesting it develops as a result of prolonged abnormal myosin VI function. Myosin VI dimerises, and the mutant protein may have dominant negative effects, impairing the dimer's motor function.

Myosin VI is expressed in the human heart, although its intracellular localisation and role(s) are not described. ${ }^{25}$ In the cochlea the function of myosin VI is unknown. Myosin VI is found in the cuticular plate of hair cells where it may be important developmentally and provide protection by restraining mechanical forces. ${ }^{22-24}$ Myosin VI is also associated with the Golgi complex and clathrin coated vesicles in several cell types, and may provide motor power for intracellular transport, exocytosis, and endocytosis. ${ }^{27}$ 33-36 Cells lacking myosin VI function have smaller Golgi complexes, and protein secretion is significantly reduced. ${ }^{36}$ Myosin VI is found in the leading edges of growth factor stimulated fibroblasts, and it may participate in cell migration and shape changes. ${ }^{37} 38$ Finally, cell division and morphogenesis in Drosophila are dependent on myosin VI function. ${ }^{38}{ }^{39}$ Thus myosin VI contributes to a broad range of cytoskeletal and cellular motility functions. In cardiomyocytes, myosin VI is likely to participate in similar functions, and the development of cardiac hypertrophy (and sensorineural hearing loss) may follow from a persistent deficiency in one or more of these functions.

\section{Conclusions}

Progressive autosomal dominant sensorineural hearing loss and mild cardiac hypertrophy may result from the expression of mutant non-muscle myosin VI. Subtle cardiac manifestations may escape detection or lead to misdiagnosis in other individuals with sensorineural hearing loss and MYO6 mutations.

\section{Authors' affiliations}

S A Mohiddin, D Tripodi, L Fananapazir, Cardiovascular Branch, National Heart, Lung and Blood Institute, National Institutes of Health, Bethesda, Maryland, USA

Z M Ahmed, T B Friedman, R J Morell, Section on Human Genetics, Laboratory of Molecular Genetics, National Institute on Deafness and Other Communication Disorders, National Institutes of Health, Rockville, Maryland 
A Griffith, Hearing Section, Neuro-Otology Branch and Section on Gene Structure and Function, Laboratory of Molecular Genetics, National Institute on Deafness and Other Communication Disorders, National Institutes of Health, Rockville, Maryland

Competing interests: none declared.

Correspondence to: Dr Robert J Morell, NIDCD/NIH 5 Research Court, Rockville, Maryland, 20850; morellr@helix.nih.gov

Received 2 July 2003

Accepted for publication 7 September 2003

\section{REFERENCES}

1 Wigle ED, Rakowski H, Kimball BP, Williams WG. Hypertrophic cardiomyopathy: clinical spectrum and treatment. Circulation 1995;92:1680-92.

2 Seidman JG, Seidman C. The genetic basis for cardiomyopathy: from mutation identification to mechanistic paradigms. Cell 2001;104:557-67.

3 Fananapazir L. Advances in molecular genetics and management of hypertrophic cardiomyopathy. JAMA 1999;281:1746-52.

4 Friedman TB, Griffith AJ. Human non-syndromic sensorineural deafness. Annu Rev Genomics Hum Genet 2003:4:341-402.

5 Van Camp G, Smith RJH. Hereditary hearing loss homepage (internet), vol 2003.

6 Cohen MM, Gorlin RJ. Epidemiology, etiology and genetic patterns. In: Gorlin RJ, Toriello HV, Cohen MM, eds. Hereditary hearing loss and its syndromes. Oxford: Oxford University Press, 1995:9-21.

7 Gorlin RJ. Genetic hearing loss with no associated abnormalities. In: Gorlin RJ, Toriello HV, Cohen MM, eds. Hereditary hearing loss and its syndromes. Oxford: Oxford University Press, 1995:43-61.

8 Towbin JA, Vatta M. Molecular biology and the prolonged QT syndromes. Am J Med 2001;1 10:385-98.

9 Schonberger J, Levy H, Grunig E, Sangwatanaroj S, Fatkin D, MacRae C, Stacker H, Halpin C, Eavey R, Philbin EF, Katus H, Seidman JG, Seidman CE. Dilated cardiomyopathy and sensorineural hearing loss: a heritable syndrome that maps to 6q23-24. Circulation 2000;101:1812-18.

10 Vincent GM, Timothy KW, Leppert M, Keating M. The spectrum of symptoms and QT intervals in carriers of the gene for the long-QT syndrome. N Engl J Med 1992:327:846-52.

11 Morrell CH, Gordon-Salant S, Pearson JD, Brant U, Fozard JL. Age- and gender-specific reference ranges for hearing level and longitudinal changes in hearing level. J Acoust Soc Am 1996;100:1949-67.

12 Schaffer AA. Faster linkage analysis computations for pedigrees with loops or unused alleles. Hum Hered 1996;46:226-35.

13 Terwilliger JD, Ott J. Handbook of human genetic linkage. Baltimore: Johns Hopkins University Press, 1994

14 Weeks DE, OH J, Lathrop GM. SLINK: a general simulation program for linkage analysis [abstract]. Am J Hum Genet 1990;47:A204.

15 Ahmed ZM, Morell RJ, Riazuddin S, Gropman A, Shaukat S, Ahmad MM Mohiddin SA, Fananapazir L, Caruso RC, Husnain T, Khan SN, Griffith AJ, Friedman TB, Wilcox ER. Mutations of MYO6 are associated with recessive deafness, DFNB37. Am J Hum Genet 2003;72:1315-22.

16 Yu B, French JA, Carrier L, Jeremy RW, McTaggart DR, Nicholson MR, Hambly B, Semsarian C, Richmond DR, Schwartz K, Trent RJ. Molecular pathology of familial hypertrophic cardiomyopathy caused by mutations in the cardiac myosin binding protein C gene. J Med Genet 1998;35:205-10.

17 Melchionda S, Ahituv N, Bisceglia L, Sobe T, Glaser F, Rabionet R, Arbones ML, Notarangelo A, Di lorio E, Carella M, Zelante L, Estivill X, Avraham KB, Gasparini P. MYO6, the human homologue of the gene responsible for deafness in Snell's waltzer mice, is mutated in autosomal dominant nonsyndromic hearing loss. Am J Hum Genet 2001;69:635-40.
18 Kubisch C, Schroeder BC, Friedrich T, Lutiohann B, El-Amraoui A, Marlin S, Petit C, Jentsch TJ. KCNQ4, a novel potassium channel expressed in sensory outer hair cells, is mutated in dominant deafness. Cell 1999;96:437-46.

19 Neyroud N, Tesson F, Denjoy I, Leibovici M, Donger C, Barhanin J, Faure S Gary F, Coumel P, Petit C, Schwartz K, Guicheney P. A novel mutation in the potassium channel gene KVLQT1 causes the Jervell and Lange-Nielsen cardioauditory syndrome. Nat Genet 1997;15:186-9.

20 Schmitt JP, Kamisago M, Asahi M, Li GH, Ahmad F, Mende U, Kranias EG, MacLennan DH, Seidman JG, Seidman CE. Dilated cardiomyopathy and heart failure caused by a mutation in phospholamban. Science 2003;299: 1410-13.

21 Csanady M, Hogye M, Forster T. Hypertrophic cardiomyopathy associated with congenital deaf-mutism. Eur Heart J 1987;8:528-34.

22 Avraham KB, Hasson T, Steel KP, Kingsley DM, Russell LB, Mooseker MS, Copeland NG, Jenkins NA. The mouse Snell's waltzer deafness gene encodes an unconventional myosin required for structural integrity of inner ear hair cells. Nat Genet 1995;11:369-75.

23 Hasson T, Gillespie PG, Garcia JA, MacDonald RB, Zhao Y, Yee AG, Mooseker MS, Corey DP. Unconventional myosins in inner-ear sensory epithelia. J Cell Biol 1997; 137:1287-307.

24 Self T, Sobe T, Copeland NG, Jenkins NA, Avraham KB, Steel KP. Role of myosin $\mathrm{VI}$ in the differentiation of cochlear hair cells. Dev Biol 1999:214:331-41.

25 Avraham KB, Hasson T, Sobe T, Balsara B, Testa JR, Skvorak AB, Morton CC, Copeland NG, Jenkins NA. Characterization of unconventional MYO6, the human homologue of the gene responsible for deafness in Snell's waltzer mice. Hum Mol Genet 1997;6:1225-31.

26 Hasson T, Mooseker MS. Porcine myosin-VI: characterization of a new mammalian unconventional myosin. J Cell Biol 1994;127:425-40.

27 Mermall V, Post PL, Mooseker MS. Unconventional myosins in cell movement, membrane traffic, and signal transduction. Science 1998;279:527-33.

28 Friedman TB, Sellers JR, Avraham KB. Unconventional myosins and the genetics of hearing loss. Am J Med Genet 1999:89:147-57.

29 Wang A, Liang Y, Fridell RA, Probst FJ, Wilcox ER, Touchman JW, Morton CC, Morell RJ, Noben-Tranth K, Camper SA, Friedman TB. Association of unconventional myosin MYO15 mutations with human non-syndromic deafness DFNB3. Science 1998;280:1447-51.

30 Weil D, Blanchard S, Kaplan J, Guilford P, Gibson F, Walsh J, Mburu P, Varela A, Levilliers J, Weston MD, et al. Defective myosin VIIA gene responsible for Usher syndrome type 1B. Nature 1995;374:60-1.

31 Liu XZ, Walsh J, Mburu P, Kendrick-Jones J, Cope MJ, Steel KP, Brown SD. Mutations in the myosin VIIA gene cause non-syndromic recessive deafness. Nat Genet 1997; 16:188-90.

32 Tullio AN, Accili D, Ferrans VJ, Yu ZX, Takeda K, Grinberg A, Westphal H, Preston YA, Adelstein RS. Nonmuscle myosin II-B is required for normal development of the mouse heart. Proc Natl Acad Sci USA 1997:94:12407-12.

33 Buss F, Arden SD, Lindsay M, Luzio JP, Kendrick-Jones J. Myosin VI isoform localized to clathrin-coated vesicles with a role in clathrin-mediated endocytosis. Embo J 2001;20:3676-84.

34 Buss F, Luzio JP, Kendrick-Jones J. Myosin VI, an actin motor for membrane traffic and cell migration. Traffic 2002;3:851-8.

35 Warner CL, Stewart A, Luzio JP, Steel KP, Libby RT, Kendrick-Jones J, Buss F. Loss of myosin VI reduces secretion and the size of the Golgi in fibroblasts from Snell's waltzer mice. Embo J 2003;22:569-79.

36 Biemesderfer D, Mentone SA, Mooseker M, Hasson T. Expression of myosin $\mathrm{VI}$ within the early endocytic pathway in adult and developing proximal tubules. Am J Physiol Renal Physiol 2002;282:F785-94.

37 Buss F, Kendrick-Jones J, Lionne C, Knight AE, Cote GP, Paul Luzio J. The localization of myosin $\mathrm{VI}$ at the golgi complex and leading edge of fibroblasts and its phosphorylation and recruitment into membrane ruffles of A431 cells after growth factor stimulation. J Cell Biol 1998;143:1535-45.

38 Geisbrecht ER, Montell DJ. Myosin VI is required for E-cadherin-mediated border cell migration. Nat Cell Biol 2002;4:616-20.

39 Deng W, Leaper K, Bownes M. A targeted gene silencing technique shows that Drosophila myosin $\mathrm{Vl}$ is required for egg chamber and imaginal disc morphogenesis. J Cell Sci 1999;112:3677-90. 